\title{
Correction to: The effects of a web-based learning environment on student motivation in a high school earth science course
}

\author{
Shiang-Kwei Wang ${ }^{1} \cdot$ Thomas C. Reeves $^{2}$
}

Published online: 27 July 2020

(c) Association for Educational Communications and Technology 2020

\section{Correction to: Educational Technology Research and Development (2006) 55(2):169-192 \\ https://doi.org/10.1007/s11423-006-9016-3, Educational Technology Research and Development (2006) 54(6):597-621 https://doi.org/10.1007/s11423-006-0638-2}

This article was unintentionally published twice in this journal, by the same authors.

The following should be considered the version of record and used for citation purposes: "Shiang-Kwei Wang, Thomas C. Reeves, The effects of a web-based learning environment on student motivation in a high school earth science course, Educational Technology Research and Development, Volume 55, Issue 2, pages 169-192, https://doi.org/10.1007/ s11423-006-9016-3".

The duplicate "Shiang-Kwei Wang, Thomas C. Reeves, The effects of a web-based learning environment on student motivation in a high school earth science course, Educational Technology Research and Development, Volume 54, Issue 6, pages 597-621, https:// doi.org/10.1007/s11423-006-0638-2" is to be ignored.

Springer apologizes to the readers of the journal for not detecting the duplication during the publication process.

The original articles can be found online at https://doi.org/10.1007/s11423-006-9016-3, https://doi. org/10.1007/s11423-006-0638-2.

Shiang-Kwei Wang

SWang@qcc.cuny.edu

1 School of Education and Professional Services, New York Institute of Technology, Old Westbury, NY, USA

2 Department of Educational Psychology and Instructional Technology (EPIT), College of Education, The University of Georgia, Atlanta, GA, USA 
Publisher's Note Springer Nature remains neutral with regard to jurisdictional claims in published maps and institutional affiliations. 